Kulturrevolution bis zur Affäre um Lin Biao. Bis hierher (S. 162) enthält das Buch nichts, was sich nicht in ähnlich geraffter Form auch in Dutzenden anderer Schriften nachlesen ließe. Tsien schildert sodann die Grundprinzipien des chinesischen Staates, dabei vom Denken Mao Tse-tungs ausgehend, die Struktur von Verwaltung, Wirtschaftssystem und Ausbildungssektor. Organisationen der Massen, Verfassungsorgane und Armee sind Gegenstand der weiteren Kapitel. Der Anhang versammelt u. a. die drei ,,ständig zu lesenden Artikel“ Maos, das (nicht mehr in Kraft befindliche ${ }^{2}$ ) Statut der Kommunistischen Partei von 1973, die (inzwischen erheblich erweiterte ${ }^{3}$ ) Verfassung von 1975, Zeittafeln, Indizes sowie eine nützliche, thematisch geordnete Bibliographie, die leider deltsche Autoren nur berücksichtigt, wenn ihre Arbeiten in englischen oder französischen Ubersetzungen vorliegen: Ein Standardwerk der internationalen Sinologie wie die fünfbändige ,,Geschichte des chinesischen Reiches" von Otto Franke findet daher keine Berücksichtigung.

Die Darstellungsweise Tsien Tche-haos verzichtet weitgehend auf Auseinandersetzung mit der wissenschaftlichen Literatur (der Autor ist allerdings ein Freund des Selbstzitates); auf chinesische Arbeiten wird recht häufig Bezug genommen. Die Beschreibung geht von den normativen Grundlagen aus, mißt sie aber meist an der Verfassungswirklichkeit. Straffung und stärkere Integration der einzelnen Abschnitte wäre oft möglich gewesen und hätte für den Leser eine Erleichterung bedeutet. Insgesamt gesehen ist das trotz der Seitenzahl handliche kleine Buch dem zu empfehlen, der Einstiegsmöglichkeiten zu möglichst vielen Problemen des gegenwärtigen politischen Systems der Volksrepublik China in einem Band vorfinden möchte.

Philip Kunig

\title{
MANFREd WoHlCKe
}

\section{Agrarstruktur und ländliche Entwicklung in Lateinamerika}

Auswahlbibliographie

Hamburg: Institut für Iberoamerika-Kunde. Dokumentationsleitstelle Lateinamerika 1978, XIII S. u. 101 S., $15 \mathrm{DM}$

Es handelt sich hierbei um eine nützliche Auswahlbibliographie überwiegend englischer und spanischer, aber auch deutsch-, französisch- und portugiesischsprachiger Literatur, vorwiegend seit 1970. Die etwa 700 Titel sind landeskundlich zusammengestellt und auch durch ein Personenregister erschlossen. Besonders nützlich ist die in diesem Dokumentationsleitstellensystem übliche Kodierung der einzelnen Titel mit schlagwortartigen Hinweisen und (meist) einer kurzen Inhaltsangabe. Die Auffindbarkeit der oft nicht leicht zugänglichen Literatur wird durch Hinweise auf die Bibliotheken, die die Arbeiten führen, erleichtert.

Rolf Hanisch

Rai.ph LeE WoOdward), JR.

\section{Central America - A Nation Divided}

Oxford University Press, New York 1976, 344 S.

Der jüngst zwischen Panama und den USA perfekte Panamakanal-Vertrag hat erneut die politische Aufmerksamkeit auf eine Region gelenkt, deren Staaten sonst eher im Schatten des allgemeinen Forschungsinteresses an den größeren Nachbarn im Norden und Süden der westlichen Hemisphäre stehen. Um so dankbarer wird der mit vergleichenden Darstellun-

\footnotetext{
2 Das neue btatut vom 18. August 1977 findet sich in China aktuell 6 (1977), S. $728 \mathrm{ff}$

3 S. Verfassungstexte, Beilage zu VRU 11 (1978), Heft 3.
} 
gen seines Forschungsbereichs nicht eben verwöhnte ,Mittelamerikanist“, wie jeden Beitrag, der die literarische Lücke verkleinern hilft, auch Woodswards Monographie zur Hand nehmen. Angereichert mit sieben Úbersichtskarten, acht Seiten Tabellen, einer kompletten politischen Chronologie, einer kurzkommentierten Auswahlbibliographie von ca. $750 \mathrm{Ti}-$ teln auf insgesamt 41 Seiten sowie etlichen textintegrierten Statistiken verfügt das Buch über ein breitgefächertes Informationsangebot. Ohne wissenschaftliche Schnörkel gibt der Autor unter neun Leitaspekten - The Isthmus (S. 3 ff.), The Kingdom of Guatemala (S. 25 ff.), Bourbon Central America (S. 61 ff.), Expectations and Achievements of Independence (S. 92 ff.), Central America and the World (S. 120 ff.), Coffee Republics (S. 149 ff.), Banana Republics (S. $177 \mathrm{ff}$.), Central America in the Age of Revolution (S. $203 \mathrm{ff}$.), The Failure of Reunification (S. 249 ff.) - einen vorwiegend historisch-politisch vergleichenden Uberblick über sämtliche Staaten Zentralamerikas südlich Mexikos und nördlich Kolumbiens. Wer allerdings präzise Detailschilderungen sucht - etwa zur Belize- und zur Panama-Frage - oder tiefergehende Untersuchungen erwartet zu den sozialen und ökonomischen Ursachen dafür, daß die Isthmus-Staaten - mit Ausnahme Costa Ricas - noch immer zu den wenigst entwikkelten der Hemisphäre gehören, dürfte bei Woodward nicht fündig werden, mit einem solchen Anliegen wohl auch das informatorische Konzept des Autors überfordern. Wie überhaupt, was die Lektüre lohnend macht, weniger die Aktualität des Materials ist, als dessen kompakt gegliederte Gesamtdarstellung: Nicht zuletzt dank des ausführlichen Registers für den Laien eine wertvolle Einführung, für den Experten ein nützliches Repetitorium.

Karl Hernekamp 